See discussions, stats, and author profiles for this publication at: https://www.researchgate.net/publication/339050523

\title{
Determinants of heat-related injuries in Australian workplaces: Perceptions of health and safety professionals
}

Article in Science of The Total Environment · February 2020

DOI: 10.1016/j.scitotenv.2020.137138

CITATIONS

0

12 authors, including:

Blesson Mathew Varghese

University of Adelaide

22 PUBLICATIONS 46 CITATIONS

SEE PROFILE

Peng Bi

University of Adelaide

276 PUBLICATIONS 5,167 CITATIONS

SEE PROFILE
READS

69

Alana Hansen

University of Adelaide

109 PUBLICATIONS 1,895 CITATIONS

SEE PROFILE

Scott Alen Hanson-Easey

University of Adelaide

56 PUBLICATIONS 321 CITATIONS

SEE PROFILE

Some of the authors of this publication are also working on these related projects:

Climate change and infectious disease in Nepal View project

Building Capacity to Curb the Public Health Impact of Emerging and Re-Emerging Infectious Diseases Due to Climate Change View project 


\section{Journal Pre-proof}

Determinants of heat-related injuries in Australian workplaces:

Perceptions of health and safety professionals

Blesson M. Varghese, Alana L. Hansen, Susan Williams, Peng Bi, Scott Hanson-Easey, Adrian G. Barnett, Jane S. Heyworth, Malcolm R. Sim, Shelley Rowett, Monika Nitschke, Ross Di

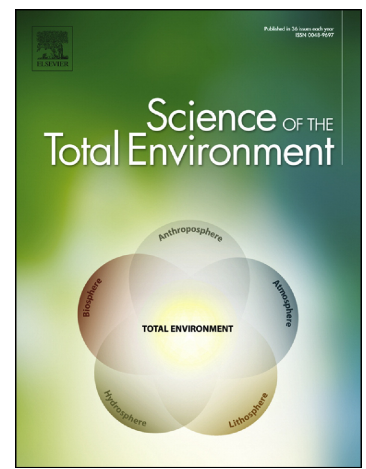
Corleto, Dino L. Pisaniello

PII: $\quad$ S0048-9697(20)30648-3

DOI: $\quad$ https://doi.org/10.1016/j.scitotenv.2020.137138

Reference: $\quad$ STOTEN 137138

To appear in: $\quad$ Science of the Total Environment

Received date: $\quad 4$ November 2019

Revised date: 6 January 2020

Accepted date: $\quad 4$ February 2020

Please cite this article as: B.M. Varghese, A.L. Hansen, S. Williams, et al., Determinants of heat-related injuries in Australian workplaces: Perceptions of health and safety professionals, Science of the Total Environment (2020), https://doi.org/10.1016/ j.scitotenv.2020.137138

This is a PDF file of an article that has undergone enhancements after acceptance, such as the addition of a cover page and metadata, and formatting for readability, but it is not yet the definitive version of record. This version will undergo additional copyediting, typesetting and review before it is published in its final form, but we are providing this version to give early visibility of the article. Please note that, during the production process, errors may be discovered which could affect the content, and all legal disclaimers that apply to the journal pertain.

(C) 2020 Published by Elsevier. 


\section{Original article}

Determinants of heat-related injuries in Australian workplaces: perceptions of health and safety professionals

\section{Authors' full name and affiliations:}

Blesson M Varghese ${ }^{1}$, Alana L Hansen ${ }^{1}$, Susan Williams ${ }^{1}$, Peng Bi ${ }^{1}$,Scott HansonEasey ${ }^{1}$, Adrian G Barnett ${ }^{2}$, Jane S Heyworth ${ }^{3}$, Malcolm R Sim ${ }^{4}$, Shelley Rowett ${ }^{5}$, Monika Nitschke ${ }^{6}$, Ross Di Corleto ${ }^{7}$, Dino L Pisaniello ${ }^{1 *}$

1 The University of Adelaide, School of Public Health, Adelaide, Australia.

2 School of Public Health and Institute of Health and Biomedical Innovation, Queensland University of Technology, Brisbane, Australia

3 School of Population and Global Health, The University of Western Australia, Crawley, Australia.

${ }^{4}$ Department of Epidemiology and Preventive Medicine, School of Public Health and Preventive Medicine, The Alfred Centre, Monash University, Melbourne, Vic., Australia.

${ }^{5}$ SafeWork SA, Government of South Australia, 33 Richmond Road, Keswick, SA, Australia

${ }^{6}$ Department for Health and Wellbeing, Government of South Australia, 11

Hindmarsh Square, Adelaide, SA, Australia

${ }^{7}$ Monitor Consulting Services, Brisbane, QLD, Australia

Corresponding author's name and complete contact information:

Professor Dino Pisaniello

School of Public Health,

University of Adelaide, Adelaide, Australia;

Tel: +61 83133571 ; Fax: +61 8313 4955;

Email address: dino.pisaniello@adelaide.edu.au

Grant information: This research is funded by the Australian Research Council (ARC Project ID DP160103059 to Dino Pisaniello). B.M.V is supported by the University of Adelaide Faculty Of Health Sciences Divisional Scholarship.

Conflict of interest: The authors declare no conflict of interest. 


\section{Abstract (299 words)}

\section{Introduction:}

Hot workplace environments can lead to adverse health effects and contribute to a range of injuries. However, there is limited contextual understanding of heat-related injury occurrence. Gaining the perspectives of occupational health and safety professionals (HSPs) may elucidate the issue and inform targeted interventions.

\section{Methods:}

A cross-sectional national online survey was conducted in Australia to characterise HSP perceptions of heat-related injuries; current preventive measures; training, policies and guidelines; and perspectives on barriers for prevention. Results were analysed descriptively and a log-Poisson regression model was used to identify risk factors associated with HSP reported injury occurrence, assessed through prevalence ratio $(\mathrm{PR})$.

\section{Results:}

Of the 307 HSP survey participants, $74 \%$ acknowledged the potential for increased risk of occupational injuries in hot weather. A variety of injury types and mechanisms were reported, including manual handling injuries, hand injuries, wounds or lacerations, and loss of control of power tools.

Correlates of reported heat-related injuries included working in the sun without shade [PR: 1.26; 95\%Cl: 1.07-1.48] and too few rest breaks [PR: 1.28; 95\%Cl: 1.04-1.44]. Other factors of significance were inadequate hydration; issues with personal protective equipment (PPE) and poor supervision of workers. Only $42 \%$ reported that adequate heat training was available and 54\% reported the provision for outdoor 
work to cease in extreme temperatures. It was acknowledged that the frequency of injuries could be reduced with wider adoption of self-pacing, and work/rest regimes.

Perceived barriers for prevention included: lack of awareness of physical injury risks, and management concerns about productivity loss and/or deadlines.

\section{Conclusion:}

The findings indicate a range of potentially modifiable work and organisational risk factors such as more suitable PPE and better supervision. More attention to these factors, in conjunction with traditional interventions to reduce heat effects, could enhance injury prevention and labour productivity in people working in hot environments.

Keywords: Occupational health; Workplace heat exposure; Work-related injuries; Perceptions; Safety professionals 


\section{Introduction}

Current and projected hot weather conditions are a serious concern for public and occupational health. ${ }^{1}$ Epidemiological studies have documented increases in morbidity and mortality associated with temperature extremes, especially among infants, young children, the elderly, those with underlying chronic health issues or disabilities and those using certain medications. However, the health risks due to extreme heat are not limited to these traditional vulnerable populations alone, but also extend to workers across a wide range of workplaces. ${ }^{2,3}$

Heat exposure in the workplace (both high temperatures and heatwaves) is known to cause adverse health effects including physical injury and illness, both acute and chronic, in workers both outdoors and in unregulated indoor environments. ${ }^{2,4,5}$ One of the well-documented direct health effects of heat exposure is heat-related illness comprising a spectrum of disorders that range from minor heat rash to heat exhaustion and heat stroke, which in severe cases can lead to death. ${ }^{6}$ These illnesses have been shown to increase with rising temperatures and during heatwaves. ${ }^{7,8}$ Heat stress also affects workers' thermal comfort and reduces worker performance, work capacity and labour productivity. ${ }^{2,9}$

Studies using administrative databases such as workers' compensation claims ${ }^{10-19}$ or company injury records ${ }^{20,21}$ and hospital records ${ }^{22}$, have identified subgroups atrisk, which include male workers, young workers, new workers, and those in outdoor and some indoor occupational settings. A range of occupational injuries have also been reported to increase in hot weather including slips, trips and falls, wounds, lacerations and amputations, burns, fractures, and superficial injuries. ${ }^{11,13,14}$ 
However, research on the antecedents or mechanisms of injuries during hot weather is limited. ${ }^{4,23}$ Additionally, the interplay of potential underlying organisational, work and personal factors that might increase the risk of work-related injuries during hot weather is not well-understood. Studies have identified these factors as potential causes of heat-related illness, but further research is needed to establish whether they play a role in injury occurrence. ${ }^{24,25}$

Cross-sectional studies assessing risk factors for heat stress-related health effects have primarily surveyed workers from a range of sectors ${ }^{24,26-33}$. Furthermore, perceptions of workers ${ }^{26,33}$ and of occupational hygienists ${ }^{34}$ regarding extreme hot weather management in a warming climate have also been explored. However, the risk factors for work injury occurrence were not the focus of these studies. ${ }^{24,26-33}$

A range of stakeholders hold occupational health and safety (OHS) roles and responsibilities, including employers and managers, OHS officers, workers themselves, health and safety professionals (HSPs), return to work coordinators and government regulatory bodies. ${ }^{35}$ The comprehensive efforts and cooperation of these stakeholders is key for the successful prevention of workplace injuries and illnesses. HSPs encompass a wide range of professional groups such as occupational hygienists, occupational physicians, OHS consultants, safety managers, OHS advisers, officers and managers. ${ }^{36}$ Their roles include, but are not limited to, performing work site inspections and evaluations, identification and assessments of risks, providing health and safety training and professional advice, policy and design, and determining ways to anticipate, eliminate, reduce or alleviate hazards. ${ }^{36}$ Given their broader role and importance in $\mathrm{OHS}$ and the growing concern about OHS risks with rising temperatures, we conducted a survey among HSPs to 
gauge their perceptions on occupational injuries during hot weather in workplaces they visit or manage.

The purposes of this study were to assess HSP perspectives on: (i) injury experiences in Australian workplaces during hot weather and contributing factors; (ii) current preventive practices; (iii) current levels of training, policies and guidelines; (iv) heat-associated productivity loss; and (v) barriers to injury prevention.

\section{Methods}

\section{Study design and participants}

An anonymous cross-sectional online survey of Australian HSPs was administered from March 2017 to April 2018. HSPs included in this survey were defined as those with a full-time responsibility in managing the health and safety of workers in several workplaces. They included 'work health and safety consultants', 'occupational health and safety coordinators', 'occupational health and safety officers', 'occupational health and safety advisors', 'occupational hygienists', 'workplace rehabilitation officers', 'return to work coordinators', 'inspectors', 'safety managers' and 'trainers'. Due to the lack of official statistics on the population frame i.e., the number of HSPS in each jurisdiction, a non-probability purposive sampling was used, and a sample size of around 250, based on the research team's experience, wider industry networks and union contacts was anticipated. Recruitment was assisted by Safe Work Australia (the peak national body for OHS in Australia), jurisdictional OHS authorities, and industry and union contacts, who promoted the survey via their websites, newsletters and networks. A brief study description and a link to the online survey were provided to these organizations, with reminder emails. 


\section{Questionnaire design and measures}

The survey questions were developed following an extensive literature review ${ }^{4}$ and discussions with experts, and made available online through SurveyMonkey following a pilot test with local HSPs in South Australia $(n=10)$. The pilot test of the survey assessed the content validity, appropriateness, and comprehensibility of the questionnaire and assisted in reducing the survey length, addressing issues and concerns with the wording of questions, and the logical flow from question to question. Based on the feedback, minor amendments were made before the questionnaire was finalized and administered online.

The opening page of the survey contained the participant information statement and informed consent was sought from all participants prior to commencement of the survey. The final questionnaire comprised seven sections namely: demographics; heat-related injuries/incidents; preventive measures; training; policies and guidelines; barriers; and productivity impact and potential solutions (see the supplementary material for the survey questions).

Specifically, to determine the perceived frequency of heat-related injuries in workplaces, HSPs were asked the following question based on a four-point Likertscale "In your experience of workplaces, would you say that injuries or incidents caused by (partly at least) hot/very humid weather occur: (never/rarely/sometimes/often)" This was followed by questions on the types of injuries/incidents, symptoms and outcomes where heat exposure could have been a direct or in-direct contributing factor. 
A five point Likert-type scale was used to assess the frequency of currently adopted prevention measures (never/rarely/sometimes/often/always) for outdoor and indoor workers. Respondents were asked their views on the most important work practice for preventing heat stress. Questions asked about the availability and type of training for preventing heat-related injuries/incidents in workplaces the respondents visit/manage. Questions also asked about the existence of a hot weather/heat stress policy, risk assessment tools used in workplaces and perceptions on the barriers for establishing prevention measures for best practice. In the final section, specific questions sought to identify HSPs perceptions on productivity concerns and potential solutions. 


\section{Data analysis}

\section{Quantitative analysis}

Data were analysed descriptively in the first instance. Not all questions were mandatory, so the actual number of participants per question was used to estimate the percentages of responses for each item. Underlying factors that may have contributed to injury experiences were assessed using the following themes: work factors and hazards; organisational issues; and types of workers. A dichotomous dependent variable was created to represent the frequency of injury experience as reported by HSPs, by combining "sometimes" and "often" versus "never" and "rarely". The five response categories for the frequency of prevention measures adopted for indoor and outdoor workers were collapsed into two categories: "often/always" and "never/rarely/sometimes" with "always/often" as the reference category.

Bivariate associations between frequency of injury experience (sometimes/often vs. never/rarely) and risk factors (organisational issues, work factors and hazards, types of workers, frequency of prevention measures) were assessed using log-poisson regression analyses. This approach was chosen over the logistic model to decrease overestimation of the risks so that the results could be expressed as prevalence ratios (PR) with 95\% confidence intervals $(\mathrm{Cl})$, with $p$-values less than 0.05 considered statistically significant. ${ }^{37,38}$ All data analysis was performed using Stata 15.

\section{Qualitative analysis}

Participants who responded in the affirmative to the question "Do you think that hot weather contributes to productivity loss?" $(\mathrm{n}=245)$ were further asked: "What potential solutions to productivity loss during hot weather have been discussed?" 
Open-ended responses were provided by 115 participants and were imported and analysed for textual content in NVivo 11 (QSR International Pty Ltd, Doncaster, Victoria, Australia).

\section{Ethical approval}

This study was approved by the Ethics committee of the University of Adelaide (approval number: $\mathrm{H}-2016-085)$, and ratified by corresponding committees of Queensland University of Technology, Monash University, and The University of Western Australia.

\section{Results}

\section{Characteristics of study participants}

Table 1 shows the demographic characteristics of the 307 participants who completed the online survey. The majority of respondents were males $(65 \%)$ and $60 \%$ of respondents were in the 35 to 54 years age group. Forty-five percent represented industries with mostly outdoor activities, while $29 \%$ were from industries with mostly indoor activities. About $40 \%$ and $32 \%$ identified as a 'Health and Safety Professional' and 'Health and Safety Manager', respectively. 
Table 1. Characteristics of the study population.

\begin{tabular}{ll}
\hline Sample Characteristics (n=307) & $\mathbf{N}(\%)$ \\
\hline State and Territory, Australia* & $\mathbf{3 0 6}$ \\
Eastern (ACT/NSW/QLD/TAS/VIC) & $120(39)$ \\
Central (SA/NT) & $145(47)$ \\
Western (WA) & $41(13)$ \\
Gender* & 306 \\
Male & $198(65)$ \\
Female & $106(35)$ \\
Unspecified & $2(0.6)$ \\
Age-group & $\mathbf{3 0 6}$ \\
18-34 years & $42(14)$ \\
$35-54$ years & $184(60)$ \\
55 years and over & $80(26)$ \\
Years of experience in health and safety* & $\mathbf{3 0 5}$ \\
Less than 5 years & $33(11)$ \\
5-10 years & $105(34)$ \\
11-20 years & $104(34)$ \\
More than 20 years & $63(21)$ \\
Industry & $\mathbf{3 0 7}$ \\
Mostly indoor activities & $88(29)$ \\
Mostly outdoor activities & $139(45)$ \\
Mixed & $80(26)$ \\
Current role in health and safety & $\mathbf{3 0 4}$ \\
Consultant & $31(10)$ \\
Health and Safety Manager & $98(32)$ \\
Health and Safety Professional & $121(40)$ \\
Other (please specify) & $27(9)$ \\
\hline
\end{tabular}

Note: *May not total to 307 due to missing values.

Abbreviations: NSW/ACT/QLD/TAS/VIC, New South Wales/Australian Capital Territory/Queensland/Tasmania/Victoria; SA/NT, South Australia/Northern Territory; WA, Western Australia.

\section{Heat-related injuries/incidents}

Three-quarters $(74 \%)$ of respondents indicated that injuries or incidents caused by hot/very humid weather occur 'sometimes' or 'often' in workplaces that they visit/manage. 'Manual handling' (musculoskeletal injuries) or 'joint/ligament injuries' 
were the main type of injuries identified by $58 \%$ of the HSPs (Figure $1 \mathrm{~A}$ ) followed by 'hand injuries' (46\%) and 'wounds or lacerations' (32\%), all of which resulted in minor outcomes such as being sent home or days off work (Figure S1A). For example, $48 \%$ of HSPs reported that 'wounds or lacerations' resulted in minor outcomes.

The four most frequently cited causes of injuries were 'injuries arising from slips, trips or falls' $(46 \%)$, 'injuries resulting from not wearing personal protective equipment (PPE)' (45\%), 'impaired vision due to fogged safety glasses' (39\%) and 'loss of control of tools leading to injury' (38\%) (Figure 1B). Respondents reported 'fatigue' $(88 \%)$ as the most frequent type of incident or illness in workers during hot weather followed by 'muscle/heat cramps' (68\%) and 'severe dehydration' (64\%) (Figure 1C) resulting in minor outcomes (being sent home or days off work) and 'any access to health care' (ambulance called /visit to Emergency Department / stay in hospital), respectively (Figure S1B). 


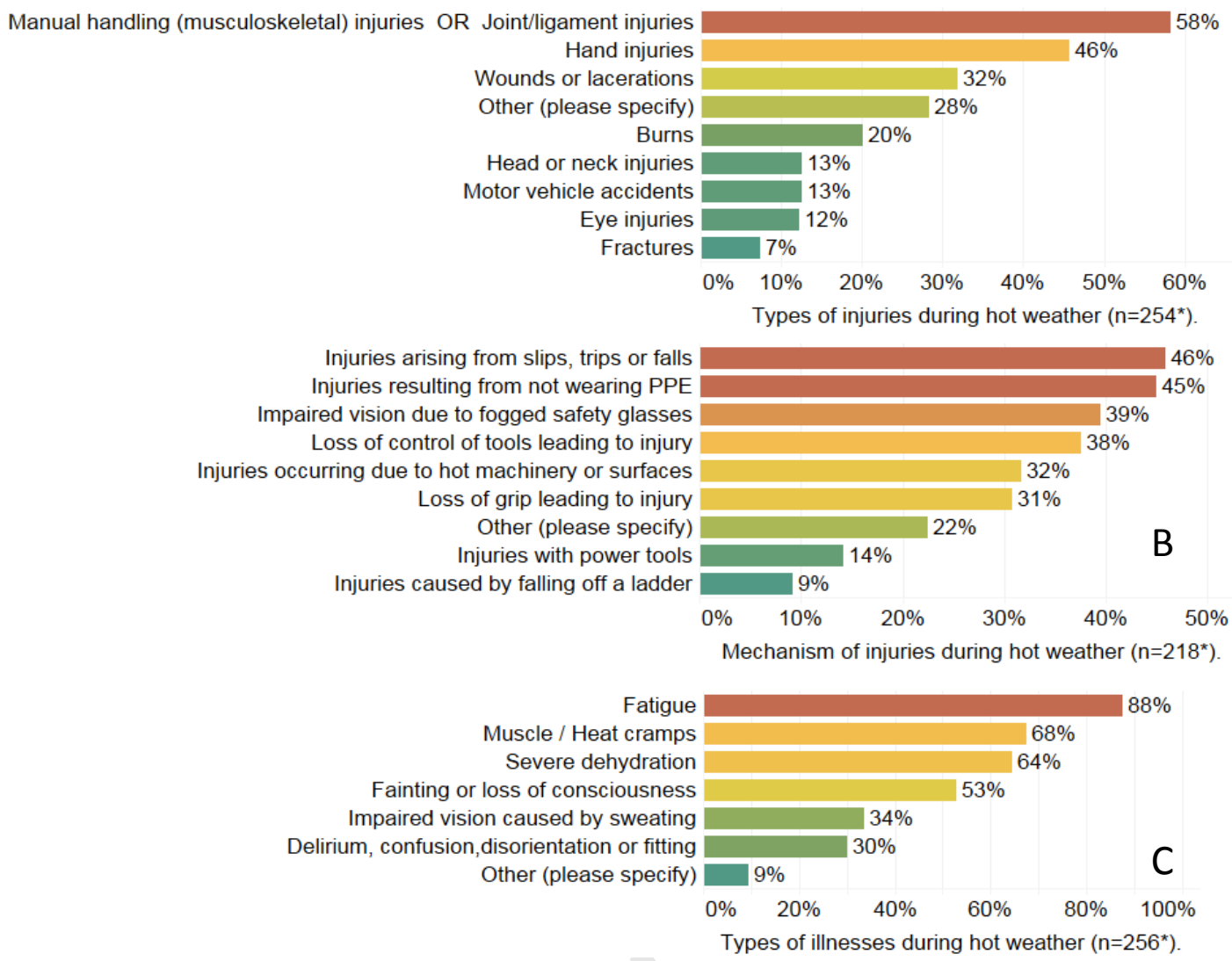

Figure 1. Bar chart of (a) types of injuries; (b) mechanism of injuries and (c) types of illnesses during hot weather as reported by respondents (as shown by the ' $n$ ' represented at the bottom of each graph). Percentages do not total $100 \%$ as multiple responses were allowed.

The major organisational issues for injuries cited by participants were 'policies not adhered to' (54\%), 'poor supervision' (40\%) and 'no health and safety training specifically on heat stress' (37\%) (Figure S2A). Organisational issues listed under the 'others' option included, 'work design and environment', 'culture within the organisation', 'management' and 'victim-blaming'. Some verbatim examples of organisational issues raised by participants include: 'aged building design issues', 'failure of air conditioning', 'poor decision making', 'lack of leadership on safety', 'culture of not managing hazards', 'workers not managing their own risks', and 'workers incorrect perception of work pressure'. 
The three most frequently cited contributing work factors and hazards for injuries were 'working in the sun with no access to shade (solar radiation)' (61\%), 'wearing of PPE leading to higher body temperature' (48\%) and 'rushed activity' (46\%) (Figure S2B). Sixty-eight percent and $47 \%$ responded that 'workers aged $25-50$ years' and 'younger workers (aged up to 24 years)', respectively were most commonly affected by injuries/incidents (Figure S2C).

\section{Preventive measures}

In response to a question asking about preventive work practices adopted for outdoor workers during hot weather, the measures most often/always adopted as cited by HSPs were 'access to cool drinking water (86\%)', 'PPE supplied' (85\%), and 'sunscreen supplied' (78\%) (Figure 2A). 'Use of cool vests' and 'urine specific gravity testing' were measures that were never/rarely adopted for outdoor workers as cited by $57 \%$ and $46 \%$ of HSPs, respectively. Measures such as 'work gets rescheduled to cooler times' and 'shade erected over work area' were adopted 'sometimes' as cited by $34 \%$ and $35 \%$ of HSPs, respectively.

For indoor workers, the measures 'fan only cooling' (30\%) and 'job rotation' $(25 \%)$ were adopted sometimes, while 'access to cool drinking water' (94\%), 'adequate ventilation' (75\%) and 'PPE supplied' (72\%) were adopted often/always (Figure 2B). 
A

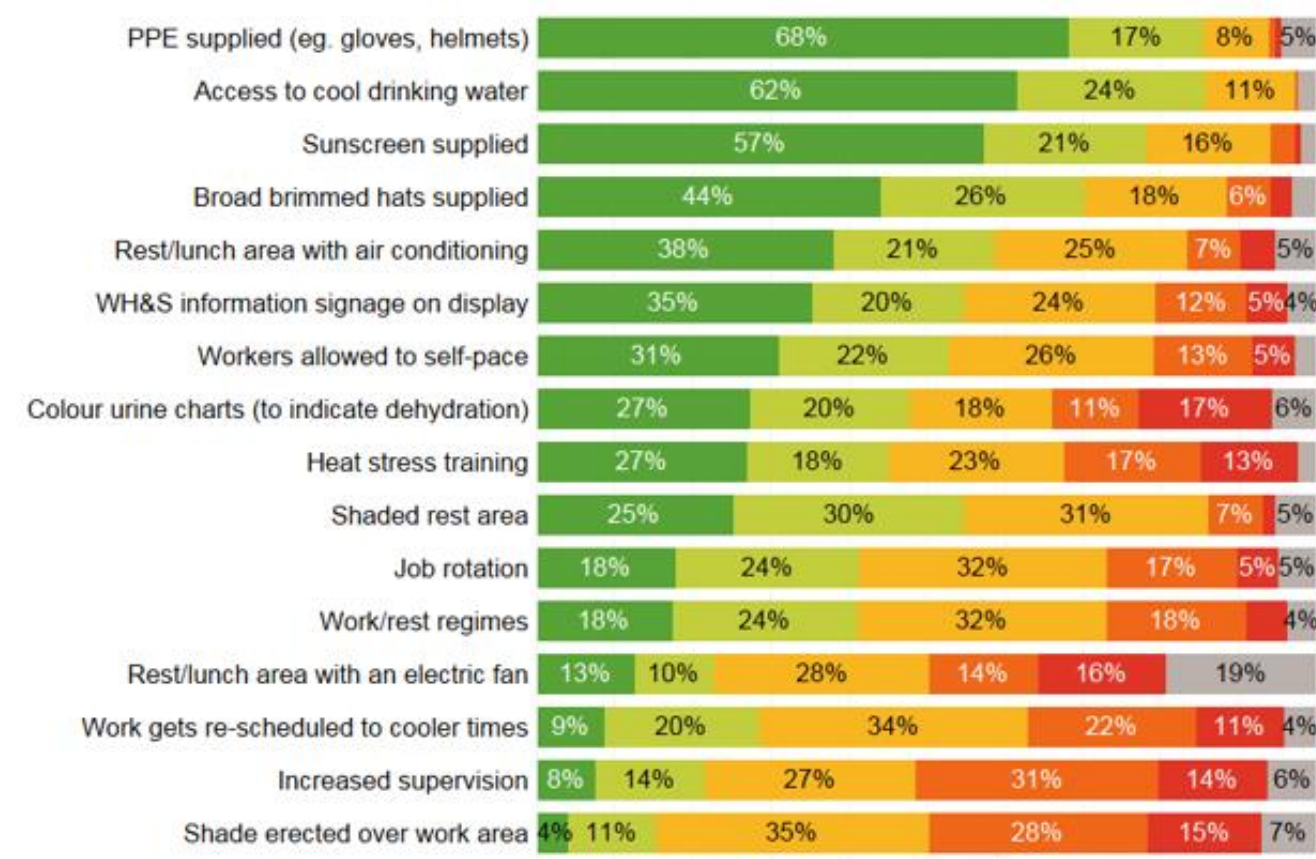

Packaged cooling systems to ventilate confined spaces

\begin{tabular}{|c|c|c|c|}
\hline $5 \% \quad 13 \%$ & $17 \%$ & $21 \%$ & $41 \%$ \\
\hline $6 \% \quad 11 \%$ & $12 \%$ & $57 \%$ & $11 \%$ \\
\hline
\end{tabular}

Response

Unsure / Don't Know / N/A

never

Rarely

Sometimes

Often

- Always

\section{B}

Access to cool drinking water PPE supplied (eg. safety goggles, gloves)

Adequate ventilation $\mathrm{H} \& \mathrm{~S}$ information signage on display Workers allowed to self-pace Shielding of heat sources Colour urine charts (to indicate dehydration) Heat stress training $5 \% \quad 16 \%$ $24 \%$ $46 \%$ $6 \%$

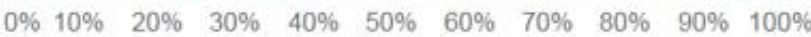
Work practices adopted during hot weather for outdoor workers $(\%)$

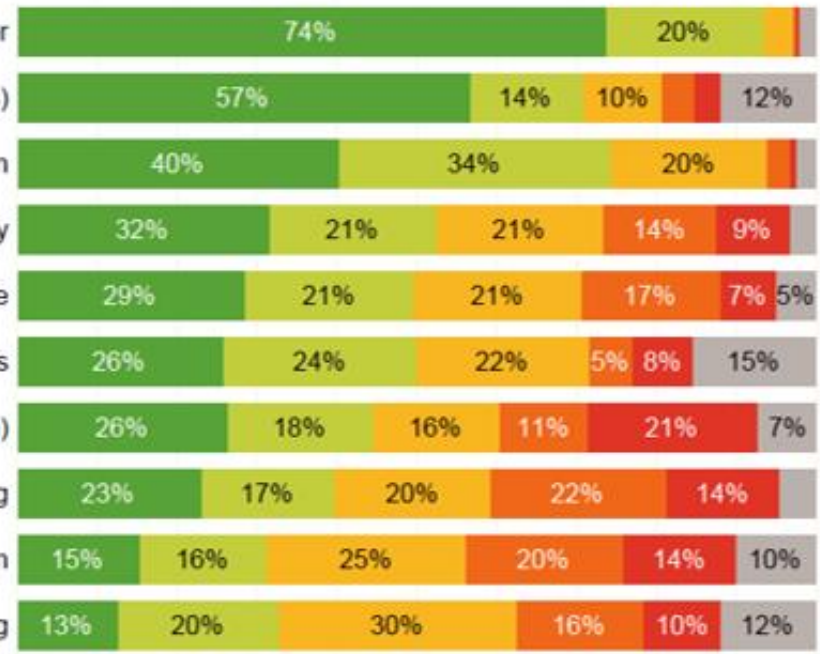

Packaged cooling systems to ventilate confined spaces Urine specific gravity testing

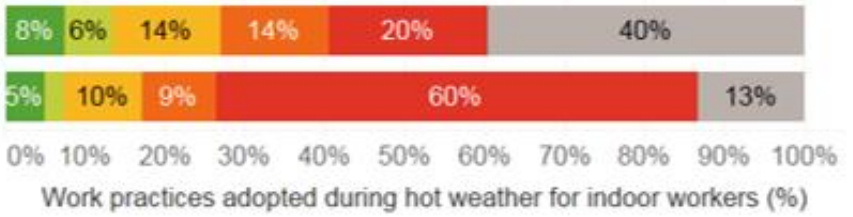

Figure 2 Percentages of work practices adopted during hot weather for outdoor $(A)$ and indoor workers (B) as cited by HSPs.

Note: values for percentages less than $4 \%$ are not displayed. 
Fifty-five percent of the participants reported that the 'provision for outdoor work to cease if temperatures are extreme' was available in workplaces that they visit/manage, with two-thirds (67\%) saying that the 'temperature at which outdoor work ceases' varies between workplaces and is dependent on other factors including humidity, location and nature of work (Table S1). With respect to work practices, participants noted that 'heat stress training' (22\%) and 'access to cool drinking water' $(19 \%)$ were the most important for preventing heat stress in outdoor work (Figure S3A)

'Access to air conditioning or fans' was often available for indoor workers as cited by $74 \%$ of respondents and the most common type of cooling systems in workplaces was 'refrigerated' (Table S1). With respect to work practices for indoor workers, participants noted that 'heat stress training' (25\%), 'air conditioning' (24\%) and 'access to cool drinking water' $(21 \%)$ were noted as important for preventing heat stress in indoor workers (Figure S3B).

\section{Training}

Forty-two percent of the HSPs reported that training was available for preventing heat-related injuries/incidents in workplaces they manage/visit, while $39 \%$ reported that it was available in some workplaces (Table S2). Fifty-two percent of the respondents said that training was available for supervisors and only $10 \%$ reported that supervisors and workers were trained separately (Table S2).

About two-thirds of the HSPs said that training was conducted 'annually regardless of job' and 'once at induction when starting a new job where heat could be a hazard' with the majority of the training being provided on site by 'health and safety 
professionals' (67\%) and 'supervisors' (46\%). With respect to the quality of the heat stress training, $45 \%$ said that the training provided was 'comprehensive' or 'adequate' while $47 \%$ of HSPs reported that this training was not assessed. The main sources of heat stress training information and resources were the 'Employer' (70\%) and 'Safety regulator' (24\%) (Table S2).

\section{Policies and guidelines}

Sixty-three percent of the participants reported that there is a hot weather or heat stress policy in workplaces they visit/manage, and $63 \%$ reported that heat stress management is partially implemented (Table S3). When asked about indicators of heat risk, about half (51\%) said that 'air temperature at weather bureau' followed by 'air temperature on site' (45\%) were used as measures to indicate heat thresholds in workplaces. With respect to the use of mobile phone device apps to assist in heat stress management, two-thirds of the HSPs (66\%) reported that they were not used in workplaces they currently visit (Table S3).

\section{Barriers}

The three most important barriers for the prevention of occupational injuries/incidents during very hot weather reported by the HSPs (Figure S4) was "lack of awareness of workers that heat can be associated with ill health and injury" (43\%), followed by "management concerns about productivity loss and/or deadlines" (33\%) and "lack of awareness by supervisors of heat hazards" (29\%).

\section{Productivity \& potential solutions}

More than half of the participants $(52 \%)$ indicated that hot weather contributes to productivity loss often, while $44 \%$ said it contributes sometimes (Table S4). When 
asked how much of a problem productivity is for workers, $58 \%$ thought it was a minor problem and $28 \%$ thought it was a major problem. Fifty-one percent of the participants reported that potential solutions have been discussed to address productivity loss in workplaces they visit/manage. The most frequent response to an open-ended question on potential solutions was to reschedule work, for example, to include earlier starts, night work or even to cooler months. Other common suggestions were: rotation of workers or tasks; active cooling systems (including air conditioning and fans); and adopting work rest regimes to ensure adequate breaks. The most common responses based on the number of coding references are shown in Figure 3.

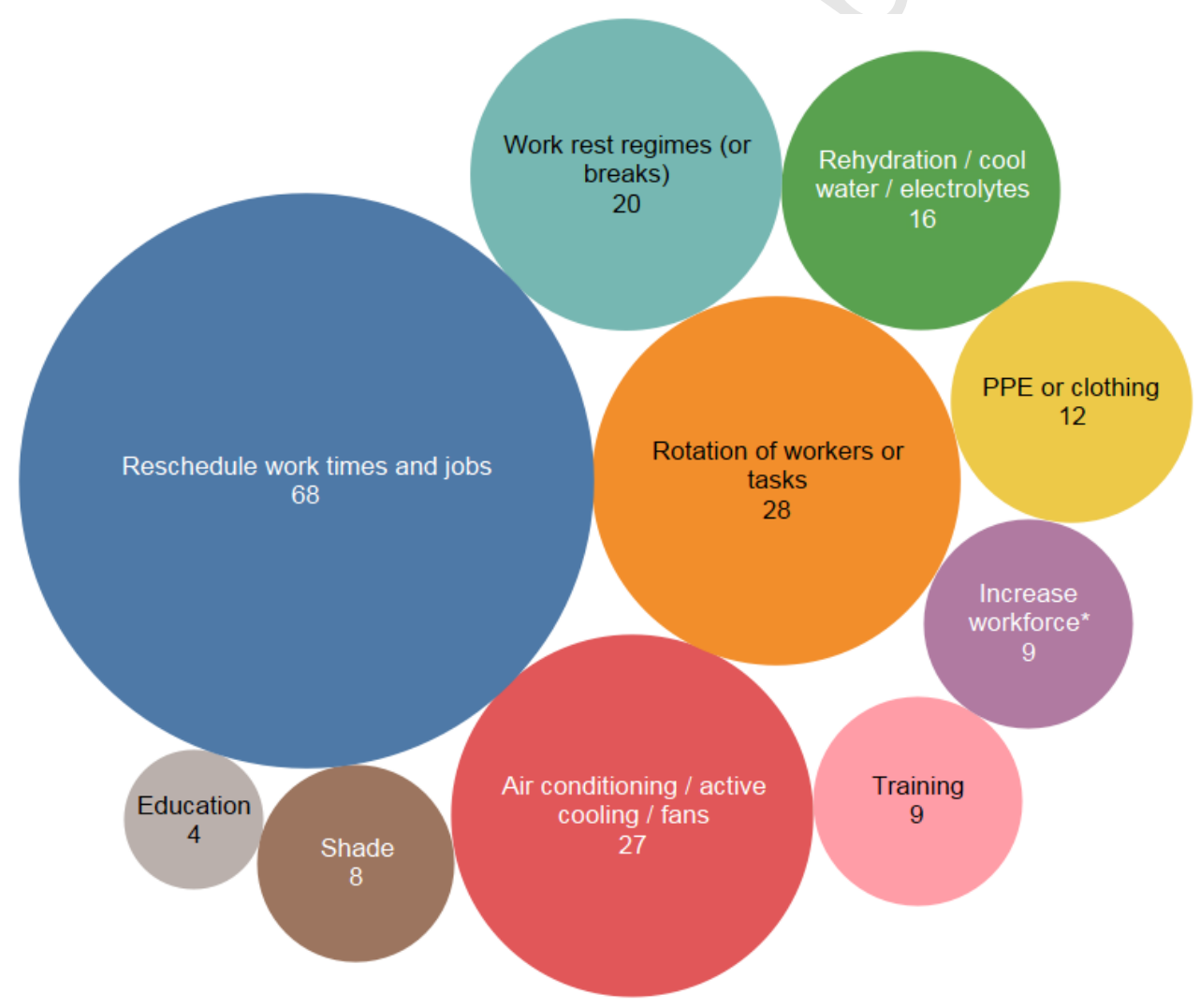

Figure 3 Open ended responses to solutions for productivity concerns. Numbers are the coding reference and circles are proportional to the number $(n=115)$.

Factors associated with injury experience 
Bivariate analyses of the organisational issues and reported frequency of injury experiences indicated a higher prevalence of injuries was associated with: 'workers not being allowed to take breaks as needed'; 'lack of induction'; 'insufficient access to cool drinking water'; 'poor supervision' and 'no health and safety training specifically on heat stress' (Figure 4). 


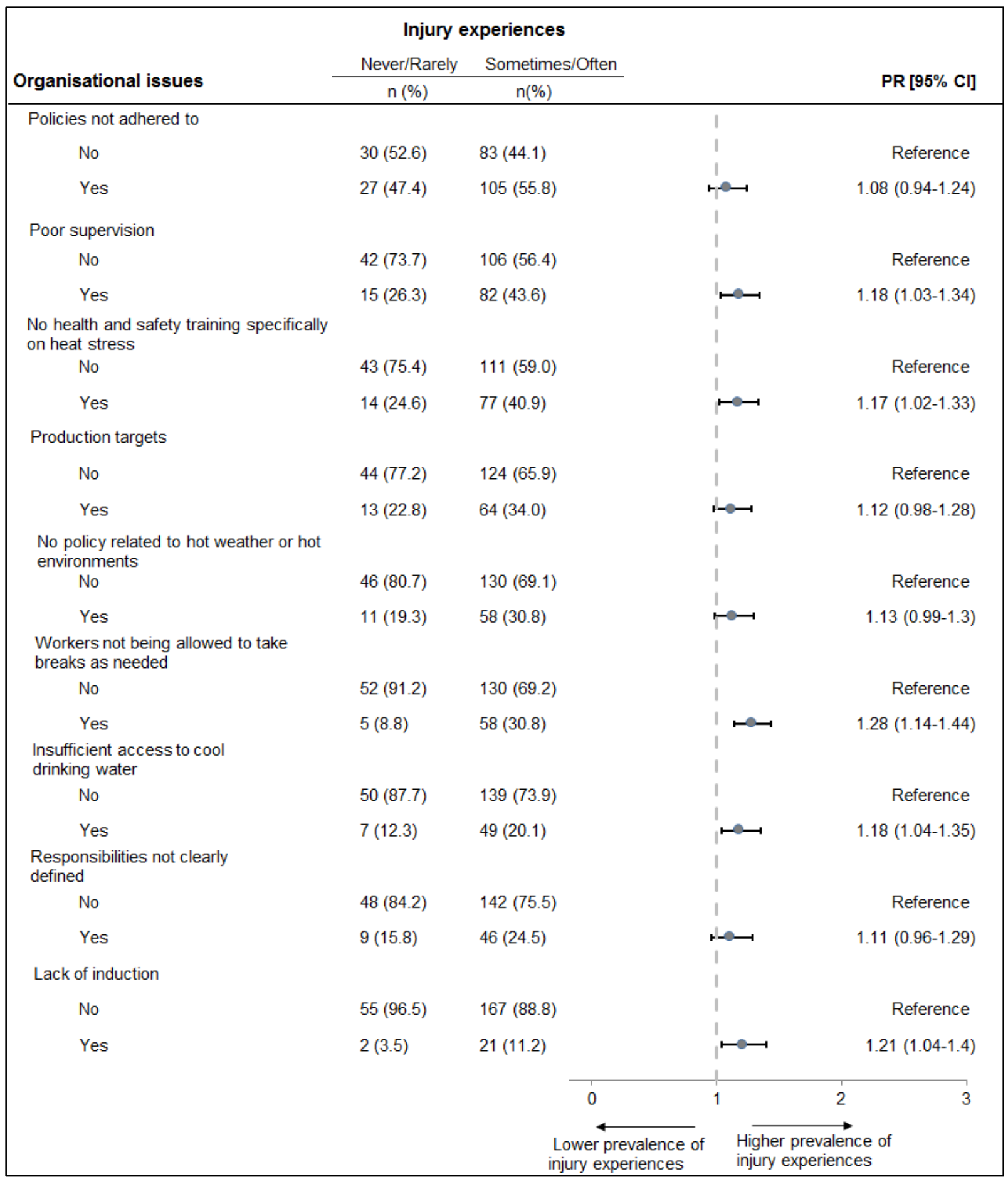

Figure 4 The associations between organisational issues cited by HSPs and reported frequency of injury experiences. Prevalence ratios and $95 \%$ confidence intervals.

With respect to work factors and hazards (Figure 5), 'working in the sun with no access to shade (solar radiation)'; 'dangerous locations'; 'wearing of PPE leading to higher body temperature'; 'fire steam and hot surfaces' and 'rushed 
activity' were identified to be associated with higher frequency of injury experiences as cited by HSPs.

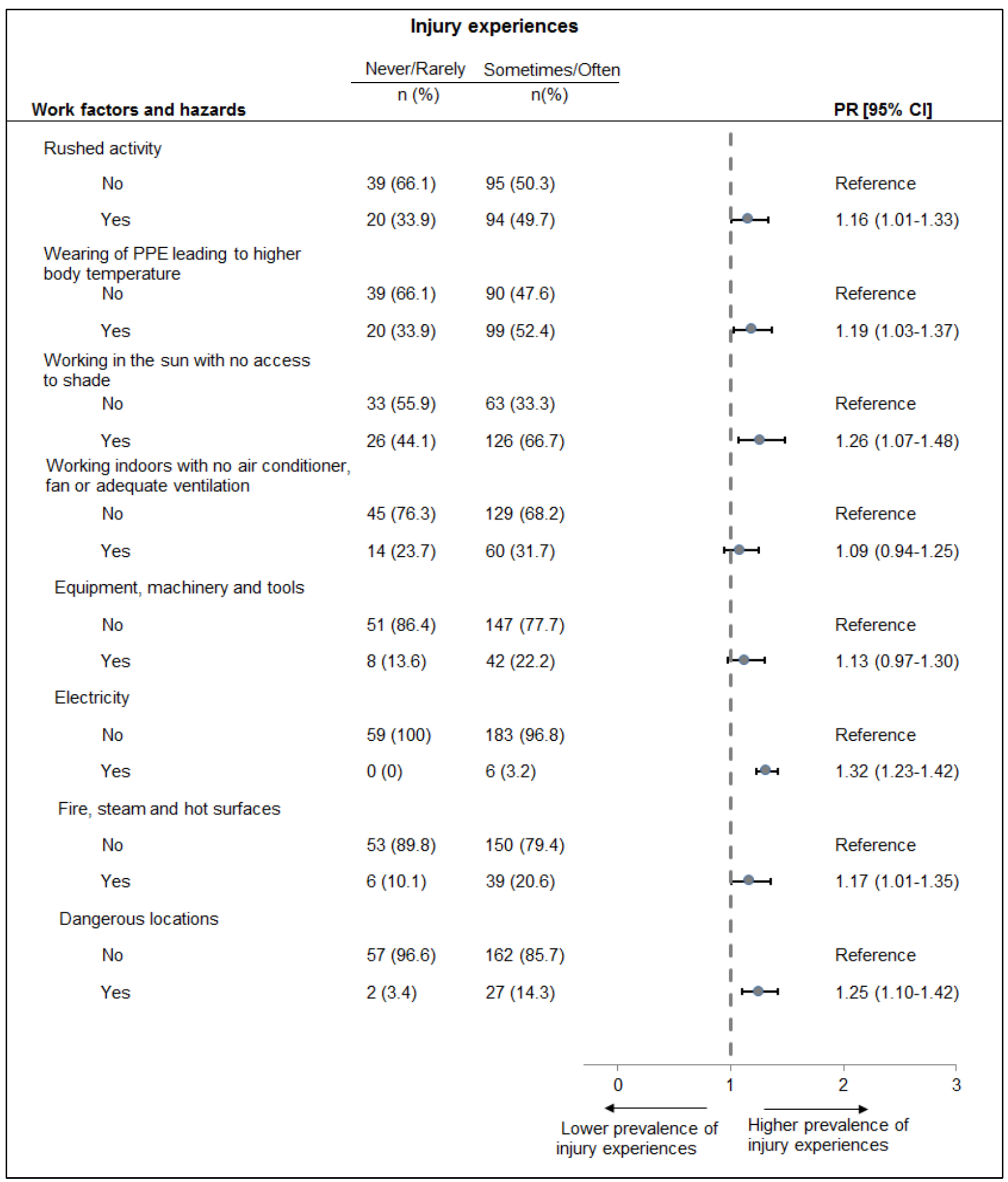

Figure 5 Prevalence ratios for injury experiences associated with work factors and hazard cited by HSPs. 
'New workers', 'young workers' and 'workers whose first language is not English' were identified as workers associated with higher frequency of injury experiences (Figure 6). Compared with workplaces where preventive work practices such as 'self-pacing'; 'work-rest regimes' and 'access to cool drinking water' are adopted often/always for outdoor workers, the frequency of injury experience (sometimes/often) was higher in workplaces where these measures were adopted never/rarely/sometimes. Similarly, if 'access to cool drinking water' and 'self-pacing' was adopted never/rarely/sometimes for indoor workers, such workplaces had higher frequency of injury experiences as cited by HSPs (Table 2). 


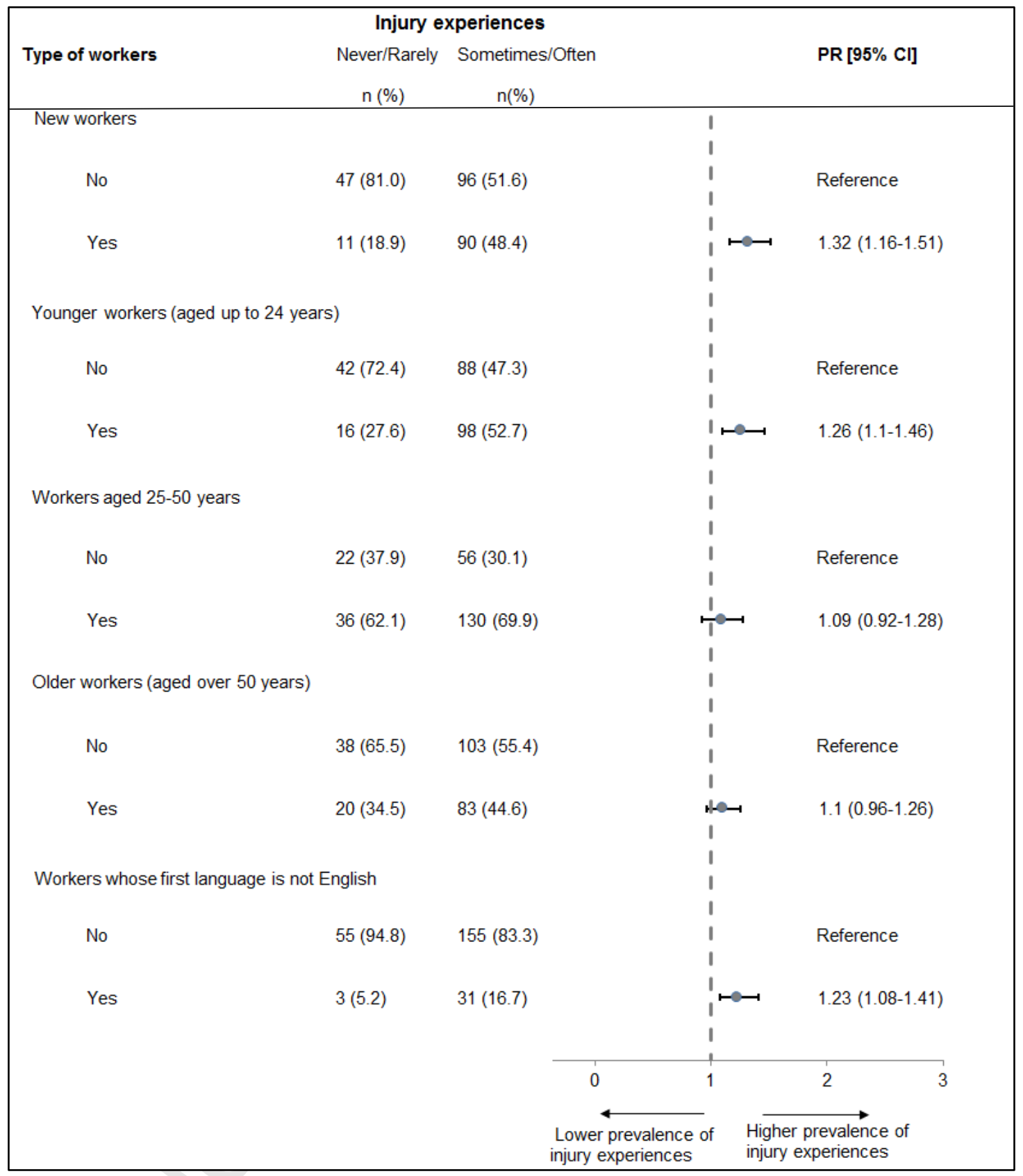

Figure 6 Prevalence ratios for injury experiences associated by worker factors as cited by HSPs.

Injury experience was reportedly lower in workplaces where air-conditioning or fans were available 'often' (reference= 'never') for indoor workers (PR 0.79; 95\%Cl: 0.64-0.97) and heat stress management was fully implemented (PR $0.72,95 \% \mathrm{Cl}: 0.59-0.89)$ compared with workplaces where it has been partially or not at all implemented (results not shown). Workplaces with a hot weather or heat stress policy had lower reported injury experience compared with those 
that did not (results not shown), however this association was not statistically significant (PR 0.92; 95\%Cl: 0.77-1.09). 


\section{Journal Pre-proof}

Table 2 Prevalence ratios (PR) for frequency of injury experiences (never/rarely vs. sometimes/often) reported by HSPs and prevention measures (never/rarely/sometimes vs. often/always).

\begin{tabular}{|c|c|c|c|c|c|c|c|}
\hline $\begin{array}{l}\text { Frequency of injury experience } \\
\text { Prevention measure for outdoor workers }\end{array}$ & $\begin{array}{c}\text { Never/ } \\
\text { Rarely } \\
\mathrm{n}(\%)\end{array}$ & $\begin{array}{c}\text { Sometimes/ } \\
\text { Often } \\
n(\%)\end{array}$ & PR $(95 \% \mathrm{Cl})$ & $\begin{array}{l}\text { Injury experience } \\
\text { Prevention measure for indoor } \\
\text { workers }\end{array}$ & $\begin{array}{c}\text { Never/ } \\
\text { Rarely } \\
\mathrm{n}(\%)\end{array}$ & $\begin{array}{c}\text { Sometimes/ } \\
\text { Often } \\
n(\%)\end{array}$ & PR $(95 \% \mathrm{Cl})$ \\
\hline Access to cool drinking water & $59(27)$ & $158(73)$ & $1.19(1.01-1.40) \Delta$ & Access to cool drinking water & $59(26)$ & $168(74)$ & $1.35(1.25-1.46) \boldsymbol{\Delta}$ \\
\hline Broad brimmed hat supplied & $47(27)$ & $129(73)$. & $1.04(0.88-1.22)$ & Shielding of heat sources & $30(25)$ & $90(75)$ & $1.04(0.90-1.22)$ \\
\hline PPE supplied & $54(26)$ & $154(74)$ & $1.13(0.92-1.37)$ & PPE supplied & $45(26)$ & $127(74)$ & $1.10(0.92-1.30)$ \\
\hline Use of cool vests & $4(22)$ & $14(78)$ & $0.95(0.73-1.23)$ & Adequate ventilation & $47(26)$ & $132(74)$ & $1.09(0.93-1.27)$ \\
\hline Sunscreen applied & $56(28)$ & $142(72)$ & $1.17(1.01-1.36) \boldsymbol{\Delta}$ & Fan only cooling & $22(29)$ & $55(71)$ & $1.08(0.91-1.28)$ \\
\hline WH\&S information signage on display & $41(30)$ & $94(70)$ & $1.15(1.00-1.34)$ & $\begin{array}{l}\text { Packaged cooling systems to ventilate } \\
\text { confined spaces }\end{array}$ & $10(31)$ & $22(69)$ & $1.10(0.85-1.42)$ \\
\hline Heat stress training & $33(29)$ & $79(71)$ & $1.10(0.95-1.28)$ & Heat stress training & $24(25)$ & $72(75)$ & $1.00(0.85-1.16)$ \\
\hline Shaded rest area & $40(30)$ & $95(70)$ & $1.13(0.97-1.31)$ & H\&S information signage on display & $33(26)$ & $93(74)$ & $1.02(0.88-1.19)$ \\
\hline Shade erected over work area & $7(19)$ & $30(81)$ & $0.89(0.74-1.06)$ & Job rotation & $24(32)$ & $51(68)$ & $1.18(0.99-1.41)$ \\
\hline Rest /lunch area with air-conditioning & $43(30)$ & $102(70)$ & $1.13(0.98-1.32)$ & Workers allowed to self-pace & $41(34)$ & $79(66)$ & $1.28(1.10-1.50) \boldsymbol{\Lambda}$ \\
\hline Rest /lunch area with an electric fan & $13(24)$ & $41(76)$ & $0.97(0.81-1.17)$ & $\begin{array}{l}\text { Colour urine charts to indicate } \\
\text { dehydration }\end{array}$ & $28(26)$ & $80(74)$ & $1.01(0.87-1.18)$ \\
\hline $\begin{array}{l}\text { Packaged cooling systems to ventilate } \\
\text { confined spaces }\end{array}$ & $4(19)$ & $17(81)$ & $0.94(0.74-1.18)$ & Urine specific gravity testing & $4(22)$ & $14(78)$ & $0.97(0.74-1.25)$ \\
\hline Workers allowed to self-pace & $46(36)$ & $83(64)$ & $1.31(1.12-1.53) \Delta$ & & & & \\
\hline Job rotation & $31(30)$ & $71(70)$ & $1.13(0.97-1.32)$ & & & & \\
\hline Increased supervision & $14(27)$ & $37(73)$ & $1.06(0.87-1.27)$ & & & & \\
\hline Work gets rescheduled to cooler times & $20(29)$ & $49(71)$ & $1.06(0.89-1.26)$ & & & & \\
\hline Work/rest regimes & $34(34)$ & $67(66)$ & $1.19(1.01-1.41) \Delta$ & & & & \\
\hline Colour urine charts (to indicate dehydration) & $27(23)$ & $90(77)$ & $0.94(0.80-1.09)$ & & & & \\
\hline Urine-specific gravity testing & $5(22)$ & $18(78)$ & $0.95(0.76-1.20)$ & & & & \\
\hline
\end{tabular}




\section{Discussion}

Hot weather creates significant OHS concerns particularly for those working outdoors and in non-air-conditioned indoor work environments. The findings described here provide insights into the experiences of work-injuries and incidents sustained during hot weather in Australian workplaces, based on the perceptions of HSPs, who are at the frontline in improving occupational safety and health.

There are several key findings from this study. First, hot/humid weather was acknowledged by the majority of the HSPs as a contributory factor to work-injuries in workplaces they visit/manage. Second, we have identified organisational issues, factors and hazards that are associated with a higher reported frequency of injury experiences. Third, it was evident that administrative and personal controls such as provision of cool drinking water, PPE and sunscreen (outdoor workers) and ventilation (indoor workers) were reportedly the most often/always adopted preventive measure. However, lack of awareness of workers and supervisors, and management concerns around productivity loss and/or deadlines were reported as key barriers for prevention. Fourth, the existence of a hot weather or heat stress policy, provision for outdoor work to cease at temperature extremes, and access to air-conditioning for indoor workers were reported by more than half of the HSPs. Fifth, heat stress training and full implementation of heat stress management was reported by less than half.

To date, studies examining the relationship between hot weather and work-injuries have not identified the mechanisms underlying this relationship. ${ }^{12,13,17,39} \mathrm{~A}$ recent review ${ }^{4}$ suggests that it is difficult to isolate ambient temperature as the sole contributory factor for work-injuries, but rather a range of personal, work-related and 
organisational factors or a combination of these factors as the most likely pathway to heat-related work injuries.

The acknowledgement by $74 \%$ of HSPs that injuries or incidents occur in hot/humid weather is concerning as this alludes to a larger problem than reported in studies using workers' compensation claims data. ${ }^{10-12,15-17,39}$ This figure is also higher than a previous study conducted in Australia in $2014^{34}$, where $53 \%$ of occupational hygienists reported having investigated circumstances around injuries or illnesses attributed to extreme heat. However, the acknowledgement of heat-related injuries/incidents that occur is not often reflected in the injuries/illnesses reported. This issue of under-reporting of heat-related injuries/illnesses is possibly due to the misunderstanding of the link between heat and health consequences. Furthermore, it is possible that the main causal factor of heat is often not reported-for example, when an individual collapses in the heat it may be attributed to the increased cardiovascular stress.

In the present study, frequently occurring heat-related injuries and symptoms of heat-related illness often resulted in minor outcomes (sent home/days off work), a notable finding which would not normally be captured using workers compensation claims data. Consistent with previous studies ${ }^{11,13}$, the types of heat-related occupational injuries frequently reported in this study included 'manual handling', 'hand injuries' and 'wound or lacerations'. 'Fatigue', 'muscle/heat cramps' and 'severe dehydration' were the commonly cited symptoms of illnesses, which is consistent with previous cross-sectional studies $24,26,29-32,40-42$ assessing risk factors for heat-related illness. These results point towards the contributory role of 
physiological factors such as fatigue, dehydration and muscle cramps as precursors to the early stages of heat-related illness and work injuries in hot weather.

Our findings suggest that consistent with previous research, ${ }^{10,13,15-18}$ new workers and young workers (aged 15-24 years) are more likely to be at risk of heat-related injuries. Furthermore, workers whose first language is not English were also identified to be at risk of heat-related injuries. The higher risks faced by these groups may be explained by factors such as lack of awareness of hazards, job inexperience, lack of familiarity within the work environment, risk-taking behaviours, and language barriers, and possible cultural factors for workers whose first language is not English. 43, 44 Additionally, these workers often feel uncomfortable raising safety concerns, and may be more likely to push through to impress their managers and other workmates due to job insecurity. In light of these findings, these groups need to be an occupational health and safety priority for regulatory bodies and policy makers.

Organisational factors such as poor safety climate and safety practices have an influence on the rates of work injuries in a workplace ${ }^{45}$ The key actors in this space include employers and workers, both of whom have shared responsibility in regards to OHS matters. By legislation, employers are required to protect the health and safety of their workers by ensuring a safe working environment 'as far as reasonably practicable, ${ }^{46}$ In the present study the organisational risk factors most often reported by HSPs as being associated with a higher frequency of heat-related injuries were: lack of health and safety training and induction, poor supervision, insufficient access to cool drinking water, and workers not allowed to take breaks as needed. This relates to structural factors in the workplace beyond the control of the individual worker that may either directly or indirectly influence the occurrence of injuries. 
Additionally, it is noteworthy that $62 \%$ of HSPs reported the existence of a hot weather policy; however, 'policies not being adhered to' was identified as an organisational issue by $60 \%$ of participants. This highlights that having a policy alone does not necessarily translate to solutions, as non-compliance can result in unsafe work environments and increased risk-taking behaviours by workers. Such policies need to be followed up with in-field interactions/discussions by leadership and HSPs in the hotter months to ensure the message is understood and controls embedded.

Work factors related to higher frequency of injuries included working in the sun with no access to shade, work in dangerous locations (e.g. confined spaces), use of PPE, work near hot surfaces and rushed activity. Although the wearing of PPE is necessary to protect workers from hazards, it can be problematic in two ways. First, PPE can be impermeable clothing or clothing with high insulating factors, potentially increasing the risk of heat stress by impeding heat loss to the environment via sweat evaporation, retaining excess heat and moisture and/or increasing the physical effort to perform tasks. ${ }^{47-50}$ Second, workers may choose not to wear PPE in hot weather because of feelings of discomfort, poor fit, and inappropriateness for a range of work circumstances. Respiratory protection devices for example can impede adequate fluid intake in hot work environments. This may result in respirators being removed in hazardous environments in order to drink fluids, resulting in exposures. Workers not wearing PPE was cited as a mechanism of injury by HSPs suggesting that the nonuse of PPE may be leaving workers exposed to other hazards. Therefore, the choice of the right PPE taking into account the work and work environment, is vital and the improvement of PPE to make it more comfortable in hot weather is needed. 
Limiting the work to suit the environment and modifying the environment to suit the work are two approaches that may be used to manage heat stress where practicable. ${ }^{51,52}$ These can be done through the hierarchy of controls to reduce hazards leading to the prevention of work-injuries and illness. ${ }^{53}$ In terms of heat hazard, the most effective higher order controls for indoor working environments would be provision of ventilation and mechanical cooling methods i.e. airconditioning and/or cooling fans, insulation of roofs and walls and shielding of heat sources. ${ }^{51,52}$ For outdoor workers, protection from the sun and the provision of an air-conditioned environment for rest breaks would be most effective. ${ }^{51,52}$ However, these controls could be expensive and impractical depending on the work environment and work settings.

Our findings that the provision of drinking water is the most common method of workplace heat stress prevention in workers (both outdoor and indoor) is consistent with other studies. $26,33,34,54,55$ However, despite access to water, $64 \%$ of HSPs cited severe dehydration as a frequent type of incident in workplaces as shown in other studies. ${ }^{29,56-59}$ Although water may be provided in workplaces, workers may still not be drinking enough, perhaps due to the inability to take adequate breaks as needed as reported by HSPs. Alternatively, as other studies have indicated, workers could be starting work dehydrated. ${ }^{56,59-61}$

The key guidance advice provided by all the eight state and territory work health and safety regulators in Australia to control heat risk includes 'reschedule work to cooler parts of the day', 'change location of work', 'job rotation' and 'extra rest breaks in cool area'. ${ }^{62}$ The lower frequency of adoption of some of these control measures (e.g. extra rest breaks) indicates the challenge faced by workplaces in terms of 
expense and the trade-off between labour productivity and worker health. Indeed, more than half of the HSPs $(53 \%)$ cited that hot weather contributed to productivity losses in workplaces and that solutions to address them have been discussed. This finding is similar to a survey of construction workers where $50 \%$ of participants reported slowing down when it is hot. ${ }^{30} \mathrm{~A}$ recent study estimated that the annual costs of heat stress to the Australian economy was US\$6.2 billion per year (or US $\$ 655$ per person) and concluded that wider adoption of prevention measures is warranted to reduce further economic impacts. ${ }^{63}$ The solutions raised by HSPs in the open-ended questions included reschedule of work to cooler times of the day and rotation of workers or tasks, while allowing workers to self-pace, and having appropriate work/rest regimes, were the measures identified as being associated with reductions in reported frequency of injury. These measures have been shown to be effective as protective measures for heat-related illness if engineering solutions are too expensive or difficult to implement. ${ }^{64}$

Provision of training and adequate supervision is another component of heat stress management, but only $42 \%$ of HSPs reported the availability of heat stress training in workplaces. Similarly, in a study of workers from South Australia, $43 \%$ of participants reported heat-stress training was available. ${ }^{33}$ Notwithstanding, it is important to acknowledge the variety of factors operating at multiple levels that may constrain the wider adoption of safe work practices. The lack of awareness by workers that heat can be associated with ill health and injury, as identified by $44 \%$ of HSPs, is an important barrier for prevention that needs to be considered. This is consistent with previous studies. $^{34,65}$ It is possible that workers and their supervisors may not be fully aware of the spectrum of health effects which can start with fatigue and 
dehydration and can progress to increased risk of accidents and heat disorders. Our previous work in Adelaide ${ }^{16}$ has shown that occupational injuries increase with temperatures even in moderate ranges (above $25^{\circ} \mathrm{C}$ ) before reaching extreme levels $\left(35^{\circ} \mathrm{C}\right)$, in both outdoor and indoor settings. Accordingly, workers and their supervisors need to be aware of the health risks of working in hot weather at both moderate and extreme temperatures. Current training programs may need to be modified to include the risks of workplace injuries that can occur at moderate temperatures, and before the occurrence of heat-related illness. It is also important that the training materials are translated or presented appropriately for non-English speaking workers, or those with poor literacy. While there is a need for raising awareness and providing training for workers, supervisors and management teams, it is also important to highlight that each of these groups have a shared responsibility in relation to OHS. Also, as pointed out earlier, training and policies are important but they must be followed up at the work front with interactions/discussions to ensure the importance is recognised and to reinforce the adoption of controls. In summary, a combination of administrative and engineering controls tailored according to individual occupations will be necessary to reduce heat-associated injuries for workers.

The present study has several limitations. First, although the study has attempted to obtain information about the extent and characteristics of occupational injury experiences during hot weather at the Australian national level, we cannot make any claims for generalisability due to the relatively small sample size and non-random sampling design. It is plausible that HSPs who were more interested in the topic may have completed the survey creating a possible selection bias whereby the frequency 
of injury may be inflated. We cannot calculate a survey response rate because we did not have a sampling frame but instead advertised the survey widely. As a proportion, there were more respondents from Central Australia than from other states. Second, the data are self-reported and the injuries/incidents reported are not validated. Third, despite our extended work ${ }^{19}$ showing differences in outcomes for occupational temperature-related injuries according to climate zones, we were unable to carry out region-specific analyses due the relatively small sizes. Fourth, respondents were not given a time-period for recalling and reporting heat-related injuries. While this could be considered a limitation, the respondents had the opportunity to reflect on relevant injuries witnessed across several workplaces in their role as HSPs without a time restriction. Fifth, the determination of "hot/humid weather" was subjective and relied upon the participant's knowledge and experiences. Hence the possibility of responses to some questions being under or overestimated cannot be ruled out.

Despite these caveats, one of the major strengths of the study is that the data collected covers several risk factors that are not normally collected as part of administrative datasets, and the first reported national study of HSPs perspectives on working in hot conditions. Garnering the perspectives of professionals at the forefront of occupational health and safety has aided in a better understanding of the underlying causes for the associations between hot weather and injuries.

\section{Conclusion}

The results of this study add to the growing body of evidence about the relationship of work injuries and hot weather, and offer additional insights on underlying factors 
that may explain the increase in risk. Our results highlight that the underlying mechanisms of injury occurrence are complex and multi-factorial involving risk factors related to the worker, the work undertaken, and the work environment. In this study, new workers, young workers, and non-English speaking workers were associated with higher injury experience in hot weather (as perceived by HSPs). Lack of shade and wearing of PPE leading to higher body temperature were identified as being important risk factors as was the inability of workers to take breaks as needed, insufficient access to cool drinking water, and poor supervision. Furthermore, preventive measures such as self-pacing and appropriate work/rest regimes were found to be associated with reduced injury experience (as perceived by HSPs). Based on these findings it is recommended that adequate attention be given to the factors identified in this study to enable prevention efforts of heat-related injuries/illnesses. Future studies may also consider exploring whether there are region-specific differences in injury experiences and adoption of prevention practices by occupations, and industries, thereby providing valuable data for the design of targeted interventions and policies. Furthermore, the findings call for action by regulators and employers for clearer, robust, and more targeted policies incorporating the occupational injury risks and risk factors, and monitoring of workers. Careful selection of PPE in the heat is also advised to avoid the extra heat strain. Translating these findings into proactive preventive action should be given a priority in the context of increasing heat exposure in Australian workplaces.

Acknowledgements: The authors would like to thank Safe Work Australia and SafeWork SA for getting involved in this study for their assistance in the 
dissemination of the survey information. All survey participants are greatly appreciated for their valuable contributions. 


\section{References}

1. Watts N, Adger WN, Agnolucci P, Blackstock J, Byass P, Cai W, et al. Health and Climate Change: Policy Responses to Protect Public Health. Lancet. 2015;386(10006):1861-914.

2. Kjellstrom T, Briggs D, Freyberg C, Lemke B, Otto M, Hyatt O. Heat, Human Performance, and Occupational Health: A Key Issue for the Assessment of Global Climate Change Impacts. Annu Rev Public Health. 2016;37:97-112.

3. Applebaum KM, Graham J, Gray GM, LaPuma P, McCormick SA, Northcross A, et al. An Overview of Occupational Risks from Climate Change. Curr Environ Health Rep. 2016;3(1):13-22.

4. Varghese BM, Hansen A, Bi P, Pisaniello D. Are Workers at Risk of Occupational Injuries Due to Heat Exposure? A Comprehensive Literature Review. Saf Sci. 2018;110, Part A,:380-92.

5. Binazzi A, Levi M, Bonafede M, Bugani M, Messeri A, Morabito M, et al. Evaluation of the Impact of Heat Stress on the Occurrence of Occupational Injuries: Meta-Analysis of Observational Studies. Am J Ind Med. 2019;62(3):233-43.

6. Jackson LL, Rosenberg HR. Preventing Heat-Related IIIness among Agricultural Workers. J Agromedicine. 2010;15(3):200-15.

7. Harduar Morano L, Bunn TL, Lackovic M, Lavender A, Dang GT, Chalmers JJ, et al. Occupational Heat-Related IIIness Emergency Department Visits and Inpatient Hospitalizations in the Southeast Region, 2007-2011. Am J Ind Med. 2015;58(10):1114-25.

8. Xiang J, Hansen A, Pisaniello D, Bi P. Extreme Heat and Occupational Heat Illnesses in South Australia, 2001-2010. Occup Environ Med. 2015;72(8):5806.

9. Levi M, Kjellstrom T, Baldasseroni A. Impact of Climate Change on Occupational Health and Productivity: A Systematic Literature Review Focusing on Workplace Heat. Med Lav. 2018;109(3):163-79. 
10. Xiang J, Bi P, Pisaniello D, Hansen A, Sullivan T. Association between High Temperature and Work-Related Injuries in Adelaide, South Australia, 20012010. Occup Environ Med. 2014;71(4):246-52.

11. Xiang J, Bi P, Pisaniello D, Hansen A. The Impact of Heatwaves on Workers' Health and Safety in Adelaide, South Australia. Environ Res. 2014;133:90-5.

12. Spector JT, Bonauto DK, Sheppard L, Busch-Isaksen T, Calkins M, Adams D, et al. A Case-Crossover Study of Heat Exposure and Injury Risk in Outdoor Agricultural Workers. PLoS One. 2016;11(10):e0164498.

13. Martinez-Solanas E, Lopez-Ruiz M, Wellenius GA, Gasparrini A, Sunyer J, Benavides FG, et al. Evaluation of the Impact of Ambient Temperatures on Occupational Injuries in Spain. Environ Health Perspect. 2018;126(6):067002.

14. Adam-Poupart A, Smargiassi A, Busque MA, Duguay P, Fournier M, Zayed J, et al. Effect of Summer Outdoor Temperatures on Work-Related Injuries in Quebec (Canada). Occup Environ Med. 2015;72(5):338-45.

15. Varghese BM, Hansen A, Nitschke M, Nairn J, Hanson-Easey S, Bi P, et al. Heatwave and Work-Related Injuries and IIInesses in Adelaide, Australia: A Case-Crossover Analysis Using the Excess Heat Factor (Ehf) as a Universal Heatwave Index. Int Arch Occup Environ Health. 2019;92(2):263-72.

16. Varghese BM, Barnett AG, Hansen AL, Bi P, Hanson-Easey S, Heyworth JS, et al. The Effects of Ambient Temperatures on the Risk of Work-Related Injuries and Illnesses: Evidence from Adelaide, Australia 2003-2013. Environ Res. 2019;170:101-9.

17. Mclnnes JA, Akram M, MacFarlane EM, Keegel T, Sim MR, Smith P. Association between High Ambient Temperature and Acute Work-Related Injury: A Case-Crossover Analysis Using Workers' Compensation Claims Data. Scand J Work Environ Health. 2017;43(1):86-94.

18. Varghese BM, Barnett AG, Hansen AL, Bi P, Nairn J, Rowett S, et al. Characterising the Impact of Heatwaves on Work-Related Injuries and 
Illnesses in Three Australian Cities Using a Standard Heatwave DefinitionExcess Heat Factor (Ehf). J Expo Sci Environ Epidemiol. 2019;[Epub ahead of print]. doi: 10.1038/s41370-019-0138-1.

19. Varghese BM, Barnett AG, Hansen AL, Bi P, Heyworth JS, Sim MR, et al. Geographical Variation in Risk of Work-Related Injuries and IIInesses Associated with Ambient Temperatures: A Multi-City Case-Crossover Study in Australia, 2005-2016. Sci Total Environ. 2019;687:898-906.

20. Garzon-Villalba XP, Mbah A, Wu Y, Hiles M, Moore H, Schwartz SW, et al. Exertional Heat IIIness and Acute Injury Related to Ambient Wet Bulb Globe Temperature. Am J Ind Med. 2016;59(12):1169-76.

21. Fogleman M, Fakhrzadeh L, Bernard TE. The Relationship between Outdoor Thermal Conditions and Acute Injury in an Aluminum Smelter. Int $\mathrm{J}$ Ind Ergon. 2005;35(1):47-55.

22. Morabito M, Cecchi L, Crisci A, Modesti PA, Orlandini S. Relationship between Work-Related Accidents and Hot Weather Conditions in Tuscany (Central Italy). Ind Health. 2006;44(3):458-64.

23. Bonafede M, Marinaccio A, Asta F, Schifano P, Michelozzi P, Vecchi S. The Association between Extreme Weather Conditions and Work-Related Injuries and Diseases. A Systematic Review of Epidemiological Studies. Ann Ist Super Sanita. 2016;52(3):357-67.

24. Spector JT, Krenz J, Blank KN. Risk Factors for Heat-Related IIIness in Washington Crop Workers. J Agromedicine. 2015;20(3):349-59.

25. Spector JT, Krenz J, Rauser E, Bonauto DK. Heat-Related Illness in Washington State Agriculture and Forestry Sectors. Am J Ind Med. 2014;57(8):881-95.

26. Zander KK, Mathew S, Garnett ST. Exploring Heat Stress Relief Measures among the Australian Labour Force. Int J Environ Res Public Health. $2018 ; 15(3)$. 
27. Pogacar T, Casanueva A, Kozjek K, Ciuha U, Mekjavic IB, Kajfez Bogataj L, et al. The Effect of Hot Days on Occupational Heat Stress in the Manufacturing Industry: Implications for Workers' Well-Being and Productivity. Int J Biometeorol. 2018;62(7):1251-64.

28. Uejio CK, Morano LH, Jung J, Kintziger K, Jagger M, Chalmers J, et al. Occupational Heat Exposure among Municipal Workers. Int Arch Occup Environ Health. 2018;91(6):705-15.

29. Hunt AP, Parker AW, Stewart IB. Symptoms of Heat Illness in Surface Mine Workers. Int Arch Occup Environ Health. 2013;86(5):519-27.

30. Moda HM, Alshahrani A. Assessment of Outdoor Workers Perception Working in Extreme Hot Climate. In: Leal Filho W, Manolas E, Azul AM, Azeiteiro UM, McGhie $\mathrm{H}$, editors. Handbook of Climate Change Communication: Vol. 3: Case Studies in Climate Change Communication. Cham: Springer International Publishing; 2018. p. 183-95.

31. Dutta P, Rajiva A, Andhare D, Azhar GS, Tiwari A, Sheffield P, et al. Perceived Heat Stress and Health Effects on Construction Workers. Indian J Occup Environ Med. 2015;19(3):151-8.

32. Mirabelli MC, Quandt SA, Crain R, Grzywacz JG, Robinson EN, Vallejos QM, et al. Symptoms of Heat Illness among Latino Farmworkers in North Carolina. Am J Prev Med. 2010;39(5):468-71.

33. Xiang J, Hansen A, Pisaniello D, Bi P. Workers' Perceptions of Climate Change Related Extreme Heat Exposure in South Australia: A CrossSectional Survey. BMC Public Health. 2016;16:549.

34. Xiang J, Hansen A, Pisaniello D, Bi P. Perceptions of Workplace Heat Exposure and Controls among Occupational Hygienists and Relevant Specialists in Australia. PLoS One. 2015;10(8):e0135040.

35. Safe Work Australia. Get the Work Health and Safety Facts. 2018 [updated 19 Dec 2018; cited 20182 Dec]. Available from: 
https://www.safeworkaustralia.gov.au/national-safe-work-month/facts\#thelatest-data

36. HaSPA (Health and Safety Professionals Alliance). The Core Body of Knowledge for Generalist Ohs Professionals [Internet]. Tullamarine, VIC: Safety Institute of Australia; 2012.

37. Lee J, Tan CS, Chia KS. A Practical Guide for Multivariate Analysis of Dichotomous Outcomes. Ann Acad Med Singapore. 2009;38(8):714-9.

38. Martinez BAF, Leotti VB, Silva GSE, Nunes LN, Machado G, Corbellini LG. Odds Ratio or Prevalence Ratio? An Overview of Reported Statistical Methods and Appropriateness of Interpretations in Cross-Sectional Studies with Dichotomous Outcomes in Veterinary Medicine. Front Vet Sci. 2017;4:193.

39. Mclnnes JA, MacFarlane EM, Sim MR, Smith P. The Impact of Sustained Hot Weather on Risk of Acute Work-Related Injury in Melbourne, Australia. Int J Biometeorol. 2018;62(2):153-63.

40. Venugopal V, Chinnadurai JS, Lucas RA, Kjellstrom T. Occupational Heat Stress Profiles in Selected Workplaces in India. Int J Environ Res Public Health. 2015;13(1).

41. Majumder J, Bagepally BS, Shah P, Kotadiya S, Yadav S, Naha N. Comparison of Workers' Perceptions toward Work Climate and Health Symptoms between Ceramic and Iron Foundry Workers. Indian J Occup Environ Med. 2016;20(1):48-53.

42. Mutic AD, Mix JM, Elon L, Mutic NJ, Economos J, Flocks J, et al. Classification of Heat-Related Illness Symptoms among Florida Farmworkers. J Nurs Scholarsh. 2018;50(1):74-82.

43. Smith PM, Chen C, Mustard C. Differential Risk of Employment in More Physically Demanding Jobs among a Recent Cohort of Immigrants to Canada. Inj Prev. 2009;15(4):252-8. 
44. Orrenius PM, Zavodny M. Do Immigrants Work in Riskier Jobs? Demography. 2009;46(3):535-51.

45. Toppazzini MA, Wiener KKK. Making Workplaces Safer: The Influence of Organisational Climate and Individual Differences on Safety Behaviour. Heliyon. 2017;3(6):e00334-e.

46. Safe Work Australia. Model Code of Practice: Managing the Work Environment and Facilities. Canberra: SWA; 2011. p. 17-8.

47. Holmer I. Protective Clothing in Hot Environments. Ind Health. 2006;44(3):404-13.

48. Xu X, Gonzalez JA, Santee WR, Blanchard LA, Hoyt RW. Heat Strain Imposed by Personal Protective Ensembles: Quantitative Analysis Using a Thermoregulation Model. Int J Biometeorol. 2016;60(7):1065-74.

49. O'Brien C, Blanchard LA, Cadarette BS, Endrusick TL, Xu X, Berglund LG, et al. Methods of Evaluating Protective Clothing Relative to Heat and Cold Stress: Thermal Manikin, Biomedical Modeling, and Human Testing. J Occup Environ Hyg. 2011;8(10):588-99.

50. Bensel CK, Santee WR. Use of Personal Protective Equipment in the Workplace. In: Salvendy G, editor. Handbook of Human Factors and Ergonomics. Hoboken, NJ: John Wiley \& Sons; 2006. p. 912-28.

51. Safe Work Australia. Guide for Managing the Risks of Working in Heat. Canberra: SWA; 2018. p. 1-13.

52. Corleto RD. Physical Hazards: Thermal Environment. In Haspa (Health and Safety Professionals Alliance), the Core Body of Knowledge for Generalist Ohs Professionals. Tullamarine, VIC: Safety Institute of Australia; 2012. p. 145.

53. Gorman T, Dropkin J, Kamen J, Nimbalkar S, Zuckerman N, Lowe T, et al. Controlling Health Hazards to Hospital Workers: A Reference Guide. New Solut. 2014;23(1_suppl):1-169. 
54. Brearley MB. Should Workers Avoid Consumption of Chilled Fluids in a Hot and Humid Climate? Saf Health Work. 2017;8(4):327-8.

55. Jacklitsch BL, King KA, Vidourek RA, Merianos AL. Heat-Related Training and Educational Material Needs among Oil Spill Cleanup Responders. Environ Health Insights. 2018;12:1178630218802295.

56. Brake DJ, Bates GP. Fluid Losses and Hydration Status of Industrial Workers under Thermal Stress Working Extended Shifts. Occup Environ Med. $2003 ; 60$.

57. Meade RD, Lauzon M, Poirier MP, Flouris AD, Kenny GP. An Evaluation of the Physiological Strain Experienced by Electrical Utility Workers in North America. J Occup Environ Hyg. 2015;12(10):708-20.

58. Meade RD, D'Souza AW, Krishen L, Kenny GP. The Physiological Strain Incurred During Electrical Utilities Work over Consecutive Work Shifts in Hot Environments: A Case Report. J Occup Environ Hyg. 2017;14(12):986-94.

59. Polkinghorne BG, Gopaldasani V, Furber S, Davies B, Flood VM. Hydration Status of Underground Miners in a Temperate Australian Region. BMC Public Health. 2013;13(1):426.

60. Miller VS, Bates GP. Hydration, Hydration, Hydration. Ann Occup Hyg. 2010;54(2):134-6.

61. Bates GP, Miller VS, Joubert DM. Hydration Status of Expatriate Manual Workers During Summer in the Middle East. Ann Occup Hyg. 2010;54(2):13743.

62. Mclnnes JA, MacFarlane EM, Sim MR, Smith P. Working in Hot Weather: A Review of Policies and Guidelines to Minimise the Risk of Harm to Australian Workers. Inj Prev. 2016;23(5):334-9.

63. Zander KK, Botzen WJW, Oppermann E, Kjellstrom T, Garnett ST. Heat Stress Causes Substantial Labour Productivity Loss in Australia. Nat Clim Chang. 2015;5:647. 
64. Miller V, Bates G, Schneider JD, Thomsen J. Self-Pacing as a Protective Mechanism against the Effects of Heat Stress. Ann Occup Hyg. 2011;55.

65. Stoecklin-Marois M, Hennessy-Burt T, Mitchell D, Schenker M. Heat-Related Illness Knowledge and Practices among California Hired Farm Workers in the Micasa Study. Ind Health. 2013;51. 


\section{Highlights}

- Work injuries increase in hot weather but risk factors are poorly understood

- Stakeholders perspectives were sought on injury risks to workers in hot weather

- An online survey of health and safety professionals across Australia was conducted

- Work and organisational factors contributed to occupational injury risks in the heat

- Attention to identified risk factors could enhance workplace injury prevention 